Bulletin d'Histoire Contemporaine de

l'Espagne

$51 \mid 2017$

Les forces politiques durant la Seconde République espagnole

\title{
Mariano Luis de Urquijo (1769-1817). Biografía política en claroscuro de un personaje y una época
}

Aleix Romero Peña

\section{CpenEdition}

\section{Journals}

Edición electrónica

URL: http://journals.openedition.org/bhce/774

DOI: 10.4000/bhce.774

ISSN: 1968-3723

\section{Editor}

Presses Universitaires de Provence

\section{Edición impresa}

Fecha de publicación: 1 junio 2017

Paginación: 269-271

ISSN: 0987-4135

\section{Referencia electrónica}

Aleix Romero Peña, «Mariano Luis de Urquijo (1769-1817). Biografía política en claroscuro de un personaje y una época », Bulletin d'Histoire Contemporaine de l'Espagne [En línea], 51 | 2017, Publicado el 09 octubre 2018, consultado el 24 septiembre 2020. URL : http://journals.openedition.org/bhce/774 ; DOI : https://doi.org/10.4000/bhce.774 
Mariano Luis de Urquijo (1769-1817). Biografía política en claroscuro de un personaje y una época ${ }^{1}$

\section{Aleix ROMERO PEÑA}

La presente tesis doctoral es una biografia política de Mariano Luis de Urquijo, uno de los personajes más relevantes de la crisis del Antiguo Régimen en España. Debido a la época de cambios que le tocó vivir, una de las ideas conductoras del texto es el carácter morboso del personaje, partiendo de la noción gramsciana del término aplicada a los fenómenos que se producen en las épocas de transición, donde lo viejo está muriendo sin que termine de nacer lo nuevo. En este sentido, Urquijo, conocido por su carácter ilustrado, no cuestionó, como burócrata que fue, los fundamentos últimos del poder, lo que tendría grandes repercusiones en la aplicación de las innovaciones que él representaba.

La investigación parte de una constatación obvia: Mariano Luis de Urquijo es uno de los malditos de la historia contemporánea española. Su adscripción al denostado siglo XVIII y su "afrancesamiento» -es decir, el firme y decidido apoyo que prestó al

1 Tesis doctoral defendida el 24 de enero de 2013 en el Departamento de Ciencias Humanas de la Universidad de La Rioja. Directores: Carlos Navajas Zubeldia (Univ. de La Rioja) y Bernat Muniesa Brito (Univ. de Barcelona). Presidente: Juan Sisinio Pérez Garzón (Univ. de Castilla-La Mancha). Secretario: Gonzalo Butrón Prida (Univ. de Cádiz). Vocales: Joseba Agirreazkuenaga (Univ. del Pais Vasco), Juan Pro (Univ. Autónoma de Madrid) y Pedro Rújula (Univ, de Zaragoza).
Rey Intruso José Bonaparte- le convierten en todo un heterodoxo, condicionando notablemente el tratamiento dispensado al personaje. En el repaso bibliográfico se hace un acopio de los estereotipos, prejuicios y anacronismos que se han asociado a Urquijo, los cuales, de forma más o menos velada, llegan hasta nuestros días. Dada la situación, se hacía perentorio recurrir a nuevas fuentes primarias que arrojasen más luz sobre aquellas facetas que yacían sepultadas bajo una carga de argumentos sin fundamentar y juicios de valor.

La Biblioteca Nacional custodia un fondo hasta entonces inédito, Papeles varios, compuesto por la documentación recopilada por Urquijo durante toda su vida que portaría consigo al partir al exilio francés. Aparte de diversos títulos de nombramientos y algunas cartas -destacando una dirigida a Godoy, un hallazgo singular por cuanto el mismo Urquijo denunció que su antiguo amigo y protector había destruido la correspondencia cruzada con él-, aparecen unas memorias manuscritas sobre su etapa al frente de la Secretaría de Estado tituladas Apuntes para la memoria sobre mi vida politica, persecuciones y trabajos padecidos en ella.

En el Archivo Histórico Nacional se encuentra gran parte de la documentación oficial sobre su trayectoria política y burocrática, distinguiéndose especialmente la correspondencia mantenida con distintas embajadas y los papeles del proceso del motín de la Zamacolada. El Archivo General de Palacio alberga parte del fondo conocido como Papeles reservados de Fernando VII, que reúne documentos incautados a la administración josefina, 
resultando particularmente relevantes las actas de los consejos privados de José I. En el Archivo del Congreso de los Diputados, en cambio, se guarda el valioso tomo que recopila los papeles sobre los Antecedentes $y$ consecuencias del fallecimiento del papa Pío VI.

En cuanto a fuentes impresas, los historiadores han manejado el Elogio funerario de D. Mariano Luis de Urquijo, ministro secretario de Estado de España, escrito supuestamente por un pariente suyo, Antonio de Beraza, y aparecido en París a los tres años de su muerte. Conviene tener en cuenta que no se trata de una biografía al uso, sino de una apología que canta las virtudes de Urquijo con una evidente finalidad política: hacer frente a las acusaciones que desde la España fernandina se vertían contra los llamados «afrancesados». No obstante, contiene algunas referencias directas del personaje que resultan de interés.

Para acabar este apartado, quiero destacar la labor de identificación de los artículos escritos por Urquijo en la Gazeta de Madrid josefina, fundándome para ello en las informaciones ofrecidas por el embajador francés La Forest. Así es como he podido recuperar una dimensión completamente olvidada del personaje y rescatar sus críticas hacia la Monarquía borbónica y sus instituciones.

La construcción de una biografia política implica el dibujo de la estructura de redes que determinan al individuo. La prosopografía, $\mathrm{o}$ análisis del background social mediante el estudio colectivo de una serie de vidas, tiene un enorme valor como herramienta para conocer el papel institucional desempeñado por Urquijo. Pese a ello, no puede obviarse el hecho de que todo individuo posee una innata capacidad de resistencia frente a su contexto, por lo que cada biografia encierra, como señala Isabel Burdiel, una transgresión. Este último aspecto adquiere una significación excepcional en el decisivo año de 1808 , momento en que viejas lealtades y fidelidades saltan por los aires dejando a los contemporáneos en la complicada tesitura de tener que tomar partido.

La biografía política de Mariano Luis de Urquijo es un buen reflejo de esta tensión. Nacido en el seno de una familia vinculada al aparato administrativo del Señorío de Vizcaya, Urquijo recibió una educación esmerada y siendo todavía muy joven entró a estudiar en la Universidad de Salamanca. Desgraciadamente, a los pocos años Urquijo tuvo que marchar apresuradamente a Madrid a causa de su maltrecha economía doméstica, poniendo punto y final a sus aspiraciones académicas. Entonces tomó una determinación sorprendente: sacar a imprenta la traducción de una obra teatral de Voltaire con un discurso sobre la necesidad de la reforma del teatro español. Se trataba de un gesto suicida, pues encerraba un triple desafío. Con los dramaturgos madrileños, porque era una defensa apasionada del neoclasicismo. Con la Inquisición, porque implicaba publicar a un autor que figuraba en el Índice de libros prohibidos, estampando además en la portada su nombre. Con la Monarquía, finalmente, porque suponía tratar temas tan políticamente delicados como el del tiranicidio en un año, 1791, que vio cómo se arreciaban los vientos revolucionarios en la vecina Francia. Urquijo, sin embargo, consiguió salir sano y salvo del trance por la protección de la poderosa influencia de la minoría ilustrada, que le consideraba uno más. Por si fuera poco, este episodio le permitió acceder a la Secretaría de Estado como oficial noveno al año siguiente.

La ascendente carrera de Urquijo en dicho organismo constituye una buena muestra del funcionamiento de las redes clientelares y de patronazgo de la época, que tenían en Manuel Godoy a uno de sus puntales. Pero nuestro personaje no era un burócrata cualquiera, sino un funcionario ilustrado que ansiaba una regeneración 
radical. Se presupone que colaboraría con las intrigas de los ministros Gaspar Melchor de Jovellanos y Francisco de Saavedra, que minaron el ascendiente del político extremeño. No obstante, cuando Saavedra enfermó, Urquijo cometió nuevamente otra transgresión, postulándose para sucederle en la Secretaría de Estado mientras reponía su salud.

Los dos años y pocos meses que duró su habilitación, y posterior interinidad, han sido elogiados como los más ilustrados del XVIII español. Destacó especialmente por culminar la obra regalista el mal llamado "cisma de Urquijo», que implicó enajenarle al papa la facultad de otorgar dispensas matrimoniales. El fomento de la ciencia y de la cultura, la protección del patrimonio, la introducción de inventos como el telégrafo o la contención de los abusos de celo inquisitorial fueron otras reformas positivas que no impedirían su destitución a finales de 1800 , a causa de la creciente oposición interna y externa.

Hasta la crisis institucional de 1808 Urquijo vivió desterrado y confinado. Fue entonces cuando Napoleón le llamó a Bayona para que contribuyera en el gobierno josefino. Nuestro personaje, que se consideraba injuriado por los Borbones, aceptó la propuesta pese a haber advertido con anterioridad de los riesgos que entrañaban los planes napoleónicos con respecto a España. Los cinco años en que se mantuvo José I en el trono resultaron el postrer intento de instaurar un gobierno ilustrado, durante los cuales Urquijo apoyó las posturas más radicales: la supresión de las órdenes regulares, la eliminación de las antiguas grandezas y títulos, la confiscación de los bienes de los emigrados o la extinción de los antiguos consejos y juntas. Muchas de las medidas, empero, tuvieron un sentido más propagandístico que efectivo.

La vida de Urquijo, culminada prematuramente a los tres años de exilio, fue un compendio de varios perfiles. Político, funcionario, escritor, emigrado..., la biografía de Urquijo es en claroscuro por presentar vertientes hasta ahora ignotas y porque las más conocidas presentan algunas sombras. Como innovador, su trayectoria se ajusta perfectamente a la definición que Franco Venturi diera sobre la Ilustración española, entendiéndola como una cosa propia de los funcionarios. Urquijo trabajó tanto para monarquías absolutistas como constitucionales, adaptándose a las circunstancias. No son extrañas las paradojas en su biografía, con contradicciones tan llamativas como que un traductor de Voltaire persiguiera desde la Secretaría de Estado la primera impresión de una versión en castellano de El contrato social, de Rousseau. Se trata, por tanto, de una biografia, característica de unos tiempos de crisis.

La tesis está realizada en la modalidad de compendio por publicaciones, recogiéndose en los apéndices cuatro artículos: «Mariano Luis de Urquijo, testigo y protagonista involuntario del motín de la Zamacolada (1804)» -aparecido en Brocar. Cuadernos de investigación histórica, $\mathrm{n}^{\circ}$ 33-; «Mariano Luis de Urquijo. Biografia de un ilustrado» -recogido en Sancho el Sabio: revista de investigación y cultura vascas, $\mathrm{n}^{\circ} \quad 34$; «Our brave sans-culotte. Mariano Luis de Urquijo según los escritos de Blanco White y Lord Holland» - publicado en Cuadernos de Historia Moderna, $\mathrm{n}^{\circ}$ 36-; y «Cuadro de grosería, desunión y chismografía: conflictos y divisiones internas en la Secretaría de Estado durante los últimos años del siglo XVIII»-Hispania nova, $\mathrm{n}^{\circ}$ 10-. Asimismo se recoge también un quinto por la estrecha relación que ofrece su contenido con la tesis: «La forja de un mito historiográfico: Mariano Luis de Urquijo, el Voltaire español»-Rúbrica contemporánea, $\mathrm{n}^{\circ} 1-$. 